\title{
Financing and pricing strategies of construction supply chain under capital constraint
}

\author{
Yuxin $\mathrm{Wen}^{1}$, Linyi $\mathrm{Wu}^{2}$, and Fengmin $\mathrm{Yao}^{1, *}$ \\ ${ }^{1}$ School of Economics and Management, Harbin University of Science and Technology, Harbin \\ 150080, China \\ ${ }^{2}$ Daqing Oilfield Co., Ltd. Underground operations branch, Heilongjiang Daqing 163000
}

\begin{abstract}
Affected by factors such as cost, the financial constraints faced by the supply chain are becoming more and more severe. This paper constructs a financing and pricing decision-making model for the construction supply chain under capital constraints, and uses Stackelberg game theory to analyze and obtain the best financing and pricing strategy for the construction supply chain under the internal and external financing modes. The study found that when centralized decision-making is adopted, there is a profit distribution model that makes the profits obtained by construction developers and contractors greater than the profits obtained in decentralized decision-making; the internal financing model of the construction supply chain is better than external financing, and can enable the construction supply chain get higher profits.
\end{abstract}

\section{Introduction}

In recent years, the construction industry has shown a steady upward trend and its development prospects are relatively bright. However, the long production cycle of construction products and the scattered work locations make the relevant enterprises have a large capital demand and a long turnover cycle. The capital problem has always been prominent in the industry. If the relevant research results of the supply chain can be applied to the management research of the construction supply chain, it will be able to solve the financial problems of the construction supply chain.

At present, most of the research on construction supply chain is still in the stage of primary model discussion and qualitative analysis. For example, Venselaar et al. think that one of the core contents of supply chain management is to further coordinate and optimize member partnerships under the premise that social relations are highly concerned[1].Li et al. believe that supply chain management is an important way for the modern development of construction enterprises which can reduce cost and increase efficiency[2]. Hêriş et al. has established a construction supply chain with multiple projects[3]. With the development of market economy, the capital demand of enterprises has been hard to match with the amount of capital provided by financial institutions. Scholars found that supply chain financing is a new method for enterprises to realize financing. Seyyed et al. designed a robust

${ }^{*}$ Corresponding author: fengmin_yao@hrbust.edu.cn 
optimization model with practical application value based on supply chain commercial credit and bank commercial credit[4]. Through the statistics and analysis of the literature on supply chain financing, Sumeer determined three main prototypes of supply chain financing: fixed asset financing[5]. Yu et al. studied the influence of different contractual relationships in the supply chain on equity financing of retailers and analyzed its important position in equity financing[6]. Huang et al. established the SCF framework based on general supply chain contracts and discussed the equilibrium strategies under the three financing modes and the bank's decision-making[7]. The above studies have explored related concepts and theories about the construction supply chain, but seldom involve the financing and pricing decisions of the construction supply chain.

This paper aim at the second-order construction supply chain with developers as the core, analyzes the financing and pricing decision problems of the construction supply chain, and improves the decision-making theory of the construction supply chain.

\section{Problem description and symbol description}

In this paper, under the EPC model, it is assumed that the two-stage construction supply chain consists of a building product developer (hereinafter referred to as the developer) and a building product contractor (hereinafter referred to as the contractor), where the developer is the construction The core enterprise of the supply chain is complete information between the two. Among them, the contractor conducts the construction after receiving a certain prepayment from the developer, and the developer is responsible for the sale of commercial housing after the construction has been completed. The final-payment is paid to the contractor after the sale ends. Due to the long construction period and the large amount of materials required, contractors are more likely to face the dilemma of insufficient funds.In this context, taking into account the possible internal and external financing situations of capital-constrained companies in the supply chain, this paper will study the internal financing model of contractors when financing developers and the application of financing from banks as members of the supply chain .

The main symbols of this article are as follows:

$c$ represents construction cost per unit area. $d$ represents land cost per unit area. $w$ represents building Quotation. $p$ represents commodity housing pricing. $B$ represents engineering prepayment. The developer and the contractor's own funds are $f_{s}$ and $f_{m} . R$ represents the risk-free rate of return. Based on the contractual relationship of the construction supply chain, the developer can borrow the surplus funds to the contractor at an interest rate of $r_{s}$. When a contractor applies for financing from a bank as a member of the supply chain, the loan interest rate is $r_{b}$. Compared with the internal financing of the construction supply chain, the external financing model has a simple structure and a clear plan, and the contractor saves the planned cost of the financing plan, so it should exist $r_{b}<r_{s}$. The interest rates of various financing methods are higher than the risk-free rate of return, so there are $R<r_{b}<r_{s} ; D(p)$ is the market demand area which is the market demand area estimated by the developer on the basis of the selling price; $q$ represents the completed area which is the approved and confirmed building area approved by the manufacturer at the time of completion. In this paper, the completed building are $q$ is regarded as "supply" building area to meet $q=a-b p(a>0, b>0)$. The supply and demand balance model is established to set the market demand of building products to meet $q=D(p)=a-b p(a>0, b>0)$. 
In addition, the subscript $S$ and $m$ are set to represent the developer and contractor respectively; The superscript $N, M$, and $B$ respectively represent the unconstrained state, the internal financing and external financing of the construction supply chain under the constraint of funds.

\section{Pricing strategies of construction supply chain under different financing modes}

When the construction supply chain has financial constraints and the cost of financing is higher for the contractor based on its own credit level, the contractor must choose the supply chain financing means to get rid of its financial difficulties. This section will analyze the pricing decisions and benefits under different financing modes, and then make comparative analysis to provide decision-making suggestions for contractors when choosing internal and external financing of supply chain.

When the construction supply chain is in a state of financial constraint, namely $B+f_{m} \leq c q^{N}$, and the developer still cannot solve the financial problem by providing prepayment to the contractor.

\subsection{Internal financing pricing model of building supply chain}

In the case of inter financing in the construction supply chain, on the basis of the prepayment $B$ to the contractor, the developer shall provide financial support to the contractor in the form of commercial credit loans at the interest rate of $r_{s}$, and at the same time, the developer shall lose the opportunity cost with a risk-free return rate of $R$. Based on the partnership, the developer has a more complete understanding of the financial ability and project status information of the contractor. Meanwhile, the financing procedures of the contractor are relatively simple and the financing is more rapid and convenient. When the developer's own capital $f_{s}$ can meet the fund gap of the contractor, then there is no capital constraint in the supply chain, namely $f_{s}+f_{m} \geq c q$. Since the prepayment $B$ is paid before construction, this amount is not regarded as a commercial credit loan, so for the convenience of calculation, let $f_{m}+B=\theta$.

when decentralized decision-making is adopted, the objective functions of developers and contractors are:

$$
\begin{gathered}
\pi_{s}^{M}=(p-w-d) q+(c q-\theta)\left(r_{s}-R\right)-B R \\
\pi_{m}^{M}=w q-(c q-\theta) r_{s}-c q
\end{gathered}
$$

According to the decision order of two-stage supply chain, the equilibrium solution is obtained by inverse induction, and proposition 1 is obtained.

Proposition 1 When decentralized decision-making is adopted, under the internal financing mode, the best wholesale price and retail price of contractors and developers are $w^{M}=\frac{a+b c\left(2 r_{s}-R+1\right)-b d}{2 b}, p^{M}=\frac{3 a+b c(R+1)+b d}{4 b}$ respectively, and the optimal completion area is $q^{M}=\frac{a-b c(R+1)-b d}{4}$.The profit of the developer 
is $\pi_{s}^{M}=\frac{[a-b c(R+1)-b d]^{2}}{16 b}-\theta r_{s}+f_{m} R \quad, \quad$ the profit of the contractor is $\pi_{m}^{M}=\frac{[a-b c(R+1)-b d]^{2}}{8 b}+\theta r_{s}$, and the profit of the construction supply chain is $\pi_{c}^{M}=\frac{3[a-b c(R+1)-b d]^{2}}{16 b}+f_{m} R$.

When centralized decision-making is adopted, the profit function of building supply chain is.

$$
\pi_{c 0}^{M}=(p-c-d) q-\left(c q-f_{m}\right) R
$$

Under the centralized decision, proposition 2 can be obtained.

Proposition 2 Under the centralized decision, when adopting the internal financing strategy, the optimal completion area of the construction supply chain is $q_{0}^{M}=\frac{a-b c(1+R)-b d}{2}$, the optimal retail price is $p_{0}^{M}=\frac{3 a+b c(R+1)+b d}{2 b}$, and the profit of the construction supply chain is $\pi_{c 0}^{M}=\frac{[a-b c(R+1)-b d]^{2}}{4 b}+f_{m} R$.

Corollary $1 \pi_{c 0}^{M}>\pi_{c}^{M}, \frac{d \pi_{s}^{M}}{d r_{s}}=-\theta<0, \frac{d \pi_{m}^{M}}{d r_{s}}=\theta>0, \frac{d \pi_{c}^{M}}{d r_{s}}=0$

Corollary 1 shows that in a capital-constrained construction supply chain, the total profit of the construction supply chain under centralized decision-making is greater than the total profit under decentralized decision-making. Since the loan interest rate between members of the construction supply chain does not affect the overall profit and output of the supply chain, it only plays a role in regulating the profit distribution within the supply chain. As the developer's commercial credit loan interest rate increases, the developer's profit decreases, which increases the contractor's profit. This shows that under the mode of internal financing of supply chain members, when the developer offers commercial credit loan interest rate increase, it will cause the contractor to increase the price per unit area, in this way the loan cost is passed on to the developer. Therefore, developers cannot make more profits by increasing the interest rate of commercial credit loans.

\subsection{External financing pricing model for building supply chain}

Under the constraint of funds, namely $f_{m} \leq c q^{N}$, the contractor can also choose external financing of supply chain to make up for the shortage of funds. When the external financing mode is adopted, it is necessary to provide the external financing service of construction supply chain through banks. For the convenience of discussion, it is assumed that the bank can provide full funds with the interest rate of $r_{b}$ based on the credit of the supply chain. In this case, the developer provides the prepayment of $B$ to maximize its own interests.For the convenience of calculation, let $f_{m}+B=\theta$.

when decentralized decisions are adopted, the profit functions of developers and contractors are:

$$
\pi_{s}^{B}=(p-w-d) q-B R
$$




$$
\pi_{m}^{B}=w q-(c q-\theta) r_{b}-c q
$$

By the same method of backward induction, we get proposition 3 .

Proposition 3 When decentralized decision making is adopted, under the external financing mode, the optimal wholesale price and retail price of contractors and developers are $w^{B}=\frac{a+b c\left(r_{b}+1\right)-b d}{2 b}, p^{B}=\frac{3 a+b c\left(r_{b}+1\right)+b d}{4 b}$ respectively, and the optimal completed area is $q^{B}=\frac{a-b c\left(r_{b}+1\right)-b d}{4}$. The profit of the developer and the contractor is $\pi_{s}^{B}=\frac{\left[a-b c\left(r_{b}+1\right)-b d\right]^{2}}{16 b}-B R, \pi_{m}^{B}=\frac{\left[a-b c\left(r_{b}+1\right)-b d\right]^{2}}{8 b}+\theta r_{b}$ respectively, and the total profit of the construction supply chain is $\pi_{c}^{B}=\frac{3\left[a-b c\left(r_{b}+1\right)-b d\right]^{2}}{16 b}+\theta r_{b}-B R$.

When centralized decision-making is adopted, the objective of the building supply chain is as a function

$$
\pi_{c 0}^{B}=p q-d p-\theta-(c q-\theta)\left(1+r_{b}\right)-B R
$$

Under the centralized decision, proposition 4 can be obtained.

Proposition 4 Under the centralized decision, when the external financing strategy is adopted, the optimal completion area of the construction supply chain is $q_{0}^{B}=\frac{a-b c\left(1+r_{b}\right)-b d}{2}$, the optimal retail price is $p_{0}^{B}=\frac{a+b c\left(r_{b}+1\right)+b d}{4 b}$, and the total profit of the construction supply chain is $\pi_{c 0}^{B}=\frac{\left[a-b c\left(r_{b}+1\right)-b d\right]^{2}}{4 b}+\theta r_{b}-B R$.

Corollary 2 For the contractor, when $r_{b}$ increases by $\Delta r_{b}\left(\Delta r_{b}>0\right)$, its profit changes by $\Delta \pi_{m}^{B}=\Delta r_{b}\left[\theta-c \frac{a-b c\left(r_{b}+0.5 \Delta r_{b}+1\right)-b d}{8 b}\right]$, and there must be $c q^{N}>G$. Since $f_{m}$ of the self-owned capital satisfies $\theta<c q^{N}$, there may be $\theta \geq G$, among which $G=c \frac{a-b c\left(r_{b}+0.5 \Delta r_{b}+1\right)-b d}{8 b}$.

Corollary 2 shows that regardless of whether decentralized or centralized decisionmaking is adopted, external financing of the construction supply chain has a direct impact on the income of developers and contractors. The increase in the interest rate of external financing of the construction supply chain will enable contractors to obtain more profits. For developers, when the external financing interest rate of the construction supply chain rises $\Delta r_{b}$, the maximum profit of the developer will decrease. This also indirectly shows that the contractor will transfer part of the increased capital cost to the developer by increasing the price per unit area.

\subsection{Comparative analysis of equilibrium results under different financing modes}

Since the internal financing of the construction supply chain can maximize the profit of the developer, when a centralized decision is adopted, $\pi_{C}^{M}>\pi_{C}^{B}$ must be satisfied and $r_{b}>R$ can be obtained. 
When distributed decision making is adopted, it must satisfy $\pi_{s}^{M}>\pi_{s}^{B}$, and the $\begin{array}{llll}\text { calculation can } \quad \text { get } \quad r_{s} \leq \psi_{s} \quad, & \text { among } & \text { which } \\ \psi_{s}=\frac{-b c^{2} r_{b}^{2}+2 c(a-b c-b d) r_{b}-R c[2 a-b c(2+R)-2 b d]}{16 \theta}+R . & \end{array}$

At the same time, if the contractor obtains the maximum profit, it must satisfy $\pi_{m}^{M}>\pi_{m}^{B}$, which can be calculated as $r_{s} \geq \psi_{m}$, it can be known that $\psi_{s} \geq \psi_{m}$ must exist, among which $\psi_{m}=\frac{b c^{2} r_{b}^{2}-2 c(a-b c-b d) r_{b}-R c[2 a-b c(2+R)-2 b d]}{8 \theta}+r_{b}$

Thus, the decision threshold is obtained, as shown in Equation (7).

$$
\left\{\begin{array}{l}
r_{b} \geq R \\
r_{b} \leq \frac{6 c((a-b d))-16 \theta}{3 b c^{2}}-R-2
\end{array}\right.
$$

Corollary 3 When the bank's financing interest rate for the contractor meets $R \leq r_{b} \leq \frac{6 c((a-b d))-16 \theta}{3 b c^{2}}-R-2$, the use of internal financing can maximize the profits of the construction supply chain members, otherwise internal financing should be abandoned.

\section{Conclusion}

Aiming at a two-stage construction supply chain composed of a contractor and a developer, this discusses the financing and pricing decisions of construction supply chain under capital constraints. From the perspective of decentralized and centralized decision-making, the completed area and pricing strategy for developers and contractors to maximize profits at the same time are determined. The main conclusions of this paper are as follows: (1) When centralized decision-making is adopted, the construction supply chain can obtain greater profits than when decentralized decision-making; (2) When the contractor's financing interest rate meets the decision threshold, choosing the internal financing model can be make the members of the construction supply chain get the maximum profit; (3) When the construction supply chain is internally financed, the interest rate of the financing service provided by one party to the other party will not affect the total revenue of the construction supply chain.; (4) Whether a decentralized decision or a centralized decision is taken, external financing of the construction supply chain has a direct impact on the revenue of developers and contractors. Since this paper only considers the construction supply chain financing and pricing decision-making problems under certain demand, future research can be extended to situations that require uncertainty.

This research is supported by the National Nature Science Foundation of China (Grant No. 71701056), and Nature Science Foundation of Heilongjiang Province (Grant No. G2018007), and Fundamental Research Foundation for Universities of Heilongjiang Province (Grant No. LGYC2018JC056).

\section{References}

1. Venselaar M, Gruis V, Verhoeven F. Implementing supply chain partnering in the construction industry: work floor experiences within a dutch housing association[J]. Journal of Purchasing and Supply Management,2015,21(1):1-8. 
2. Li $\mathrm{X}, \mathrm{Du} \mathrm{J} \mathrm{X}$. Discussion on supply chain management model of construction enterprises [J]. Hubei Agricultural Mechanization,2019(14):29-30.

3. Hêriş G. Optimal integration of the facility location problem into the multi-project multi-supplier multi-resource Construction Supply Chain network design under the vendor managed inventory strategy[J]. Expert Systems With Applications,2020,139:120.

4. Seyyed H A, Armin J. Supply chain network design using trade credit and bank credit: A robust optimization model with real world application[J]. Computers \&Industrial Engineering,2018,125:69-86.

5. Sumeer C, Donato M, Janet G. Exploring the relationship between mechanisms,actors and instruments in supply chain finance:A systematic literature review[J]. International Journal of Production Economics,2019,216:1-20.

6. Yu H, Deng J. Analysis of supply chain contract structure of retailers' equity financing [J].China Management Science 27(3):41-52.

7. Huang J,Yang W S,Tu Y L.Financing mode decision in a supply chain with financial constraint[J]. International Journal of Production Economics,2020,220(2):1-12. 